\title{
Antibody to CD-18 Exerts Endothelial and Cardiac Protective Effects in Myocardial Ischemia and Reperfusion
}

\author{
Xin-Liang Ma, Philip S. Tsao, and Allan M. Lefer \\ Department of Physiology, Jefferson Medical College, Thomas Jefferson University, Philadelphia, Pennsylvania 19107
}

\begin{abstract}
We studied the effects of MAbR15.7, an antibody directed against the common $\beta$-chain (CD-18) of a family of neutrophil adherence glycoproteins, on endothelial dysfunction and myocardial injury in a model of myocardial ischemia and reperfusion in cats. Pentobarbital-anesthetized cats were subjected to $1.5 \mathrm{~h}$ occlusion of the left anterior descending coronary artery (LAD) and $4.5 \mathrm{~h}$ of reperfusion. MI $+\mathrm{R}$ resulted in severe myocardial injury and endothelial dysfunction, including signifcant elevation of plasma creatine kinase (CK) activity, marked myocardial necrosis, high cardiac myeloperoxidase (MPO) activity in ischemic cardiac tissue, and loss of response of LAD coronary rings to the endothelium-dependent vasodilators, acetylcholine (ACh) and A-23187. In contrast, MAbR15.7-treated cats exhibited a lower plasma CK activity at every time point observed after $2 \mathrm{~h}$, a reduced area of cardiac necrosis ( $2 \pm 1 \mathrm{vs}$. $30.8 \pm 2.5 \%$ of area-at-risk, $P<0.001$ ), lower MPO activity in the ischemic region $(P<0.01)$, and significantly preserved vasorelaxant responses of LAD coronary rings to endotheliumdependent vasodilators, ACh $(P<0.001)$, and A-23187 (P $<0.001$ ). These results indicate that myocardial ischemia and reperfusion induces significant myocardial injury and endothelial dysfunction in the cat involving a CD18-dependent neutrophil adherence mechanism. Inhibition of neutrophil adherence to the endothelium exerts significant protective effects in this model of reperfusion injury. (J. Clin. Invest. 1991. 88:12371243.) Key words: endothelial dysfunction • endothelium derived relaxing factor $\bullet$ neutrophil adhesive proteins $\bullet$ myeloperoxidase $\bullet$ coronary artery rings $\bullet$ acetylcholine
\end{abstract}

\section{Introduction}

Early reperfusion remains the most effective way to curtail infarct extension and improve ventricular function. However, accumulating evidence indicates that reperfusion itself may have deleterious effects on the ischemic myocardium (1-3) and that neutrophils play a critical role in reperfusion injury $(4,5)$. It has been demonstrated that either depletion of neutrophils before coronary occlusion or pharmacologically suppressing neutrophil activation exerts a significant protective effect on ischemia-reperfusion induced myocardial damage $(6,7)$. Furthermore, it has been demonstrated that monoclonal antibod-

Address correspondence and reprint requests to Dr. Allan M. Lefer, Department of Physiology, Jefferson Medical College, 1020 Locust Street, Philadelphia, PA 19107.

Received for publication 6 March 1991 and in revised form 10 May 1991.

J. Clin. Invest.

(c) The American Society for Clinical Investigation, Inc. $0021-9738 / 91 / 10 / 1237 / 07 \quad \$ 2.00$

Volume 88, October 1991, 1237-1243 ies that bind to the neutrophil adhesion-promoting glycoproteins (e.g., CD11/CD18), inhibit neutrophil aggregation and adhesion on natural and artificial substrates (8). Recently, it has been shown that anti-Mol 904, an antibody directed against one of the three alpha chains (i.e., CD1 1b) of the neutrophil adhesive glycoprotein family, has a significant cardiac protective effect in myocardial ischemia and reperfusion in canine hearts (9), and MAbR 15.7 appears to protect when given soon after occlusion in primates subjected to myocardial ischemia (10).

MAbR15.7, a novel IgG1 monoclonal antibody directed against the common $\beta$-chain (CD18) of the neutrophil adherence glycoproteins is particularly effective at blocking a wide spectrum of neutrophil adherence related events and inhibiting neutrophil localization in ischemic canine myocardium (11), but its effect on endothelial function and myocardial injury induced by ischemia/reperfusion is unknown. Therefore, the purposes of this study were to $(a)$ evaluate the effect of MAbR15.7 given shortly before reperfusion on infiltration and accumulation of neutrophils into the ischemic cat myocardium, a reproducible model of ischemia and reperfusion; and (b) investigate the effects of MAbR 15.7 on endothelial dysfunction and myocardial injury induced by myocardial ischemia followed by reperfusion.

\section{Methods}

Adult male cats (2.5-3.4 kg) were anesthetized with sodium pentobarbital $(30 \mathrm{mg} / \mathrm{kg}$, i.v.). An intratracheal cannula was inserted through a midline incision, and all cats were placed on intermittent positive-pressure ventilation (small animal respirator; Harvard Apparatus Co., Inc., Dover, MA). A polyethylene catheter was inserted into the right external jugular vein for infusion of drugs or their vehicle and another polyethylene catheter was positioned in the abdominal aorta through left femoral artery for measurement of mean arterial blood pressure $(\mathrm{MABP})^{1}$ via a pressure transducer (Statham P23AC; Gould, Inc., Cleveland, $\mathrm{OH}$ ). A midsternal thoracotomy was performed, the pericardium was opened, and a 2-0 silk ligature was placed around the left anterior descending coronary artery (LAD) 8 to $10 \mathrm{~mm}$ from its origin. Standard lead II of the scalar electrocardiogram (ECG) was used to determine heart rate (HR) and ST segment elevation. The ECG and MABP were continuously recorded on a Grass Instrument $\mathrm{Co}$. model 7 oscillographic recorder (Quincy, MA). ST-segment elevations were determined manually from an ECG recording at $25 \mathrm{~mm} / \mathrm{s}$ every $20 \mathrm{~min}$. The pressure-rate index (PRI), an approximation of myocardial oxygen demand, was calculated as the product of MABP and HR divided by 1,000 .

Experimental protocol. After completing all surgical procedures, the cats were allowed to stabilize for $30 \mathrm{~min}$ and a baseline reading of

1. Abbreviations used in this paper: $\mathrm{ACh}$, acetylcholine; CK, creatine kinase; ECG, electrocardiogram; HR, heart rate; ICAM-1, intercellular adhesion molecule-1; LAD, left anterior dedescending coronary artery; LCX, left circumflex; MABP, mean arterial blood pressure; MPO, myeloperoxidase; PRI, pressure-rate index; PVC, premature ventricular contractions. 
ECG and MABP was made and an initial blood sample was drawn. MI was produced by tightening the previously placed reversible ligature around the LAD to completely occlude the vessel. Cats were then randomly assigned to each group. This was designated as time 0 . After 1.5 $\mathrm{h}$ of ischemia, the LAD ligature was untied and the ischemic myocardium was reperfused for $4.5 \mathrm{~h}$, resulting in a total postocclusion period of $6 \mathrm{~h}$. $10 \mathrm{~min}$ before reperfusion, the monoclonal antibody directed against CD18 (MAbR15.7) (Boehringer-Ingelheim, Ridgefield, CT) or a nonbinding control antibody of the $\mathrm{IgG}_{1}$ group (MAbR3.1) was given intravenously as a bolus. Animals were randomly divided into two groups: (a) MI + MAbR3.1 $(n=6) ;(b) \mathrm{MI}+$ MAbR 15.7, $1 \mathrm{mg} / \mathrm{kg}(n=$ 7). A dose of $1 \mathrm{mg} / \mathrm{kg}$ of MAbR 15.7 was selected because this dose was found to be in excess of that necessary to exert a 100\% block of CD-18 at 5-6 $\mathrm{h}$ in primates. Additionally, preliminary studies showed that 0.5 $\mathrm{mg} / \mathrm{kg}$ of MAbR 15.7 was only partially effective in protecting the ischemic myocardium. Moreover, flow cytometry of isolated neutrophils show cross-reactivity of MAbR 15.7, but not MAbR3.1, with cat neutrophils at comparable doses to that of primates.

Plasma creatine kinase analysis. Arterial blood samples $(2 \mathrm{ml})$ were drawn immediately before ligation and hourly thereafter. The blood was collected in polyethylene tubes containing $200 \mathrm{IU}$ of heparin sodium. Samples were centrifuged at $2,000 \mathrm{~g}$ and $4^{\circ} \mathrm{C}$ for $20 \mathrm{~min}$ and plasma was removed for biochemical analysis. Plasma protein concentration was assayed using the biuret method (12). Plasma creatine kinase (CK) activity was measured in a blind manner using the method of Rosalki (13) and expressed as IU per milligram of protein.

Myocardial tissue analysis. At the end of the $6 \mathrm{~h}$ experimental period, the ligature around the LAD was retightened. Then, $30 \mathrm{ml}$ of $0.5 \%$ Evans blue was injected into the left atrium to stain that area of myocardium that was perfused by the patent coronary arteries. The area-at-risk was thus determined by negative staining. The heart was rapidly excised and placed in warmed, oxygenated Krebs-Henseleit solution. The left circumflex (LCX) and the LAD coronary arteries were isolated and removed for the subsequent study of coronary ring vasoactivity. Then the right ventricle and great vessels were removed and the left ventricle was sliced parallel to the atrioventricular groove in 3-mm thick sections. The unstained portion of the myocardium (i.e., the total area-at-risk) was separated from the Evans blue stained portion of the myocardium (i.e., the area-not-at-risk). The area-at-risk was again sectioned into $1-\mathrm{mm}$ thick slices and incubated in $0.1 \%$ nitroblue tetrazolium in phosphate buffer at $\mathrm{pH} 7.4$ and $37^{\circ} \mathrm{C}$ for $15 \mathrm{~min}$. The tetrazolium dye forms a blue formazan complex in the presence of coenzymes and dehydrogenases. The irreversibly injured or necrotic portion of the myocardium at risk which did not stain was separated from the stained portion of the myocardium (i.e., the ischemic but non-necrotic area). All three portions of the left ventricular myocardium (i.e., non-ischemic, ischemic non-necrotic, and ischemic necrotic) were weighed and the results expressed as the area-at-risk determined as a percentage of the total left ventricular mass, and the area of necrotic tissue computed as a percentage of the area at risk and as a percentage of the total left ventricular mass. The three portions of the myocardium were then stored at $-70^{\circ} \mathrm{C}$ for later assay of myeloperoxidase activity which was done in a blinded manner.

Validation experiments. In six additional cats subjected to myocardial ischemia for $90 \mathrm{~min}, 15-\mu \mathrm{m}$ microspheres having a specific activity of $15 \mathrm{mCi} / \mathrm{g}$ of ${ }^{85} \mathrm{Sr}$ and ${ }^{141} \mathrm{Ce}$ ( $3 \mathrm{M}$ Company, Minneapolis, $\mathrm{MN}$ ) were injected into the left atrium at zero time and at $90 \mathrm{~min}$ postocclusion of the LAD coronary artery. Duplicate samples of endocardium and epicardium from ischemic myocardial were counted. Control myocardial blood flow was $1.75 \pm 0.15$, ischemic epicardial flow was $0.14 \pm 0.03$, and endocardial flow was $0.12 \pm 0.04 \mathrm{ml} / \mathrm{min} / \mathrm{g}$ of tissue. These ischemic values are only $7-8 \%$ of control values, and indicate a very small collateral flow under conditions of these experiments. Additionally, the MAbR15.7 was found not to influence creatine kinase activity when added directly to plasma from ischemic cats or to alter myeloperoxidase activity when added to cardiac tissue homogenates. Moreover, the antibody does not interfere with the tetrazolium staining when added to ischemic myocardial tissue.
Isolated coronary ring studies. Both LAD and LCX coronary segments removed were placed into warmed K-H buffer consisting of (in $\mathrm{mM}$ ): $\mathrm{NaCl}, 118 ; \mathrm{KCl}, 4.75 ; \mathrm{CaCl}_{2} \cdot 2 \mathrm{H}_{2} \mathrm{O}, 2.54 ; \mathrm{KH}_{2} \mathrm{PO}_{4}, 1.19$ $\mathrm{MgSO}_{4} \cdot 7 \mathrm{H}_{2} \mathrm{O}, 1.19 ; \mathrm{NaHCO}_{3}, 12.5$; and glucose, 10.0. Isolated coronary vessels were cleaned and cut into rings of 2 to $3 \mathrm{~mm}$ in length. The rings were then mounted on stainless steel hooks, suspended in 10-ml tissue baths, and subsequently connected to FT-03 force displacement transducers (Grass Instrument Co.) to record changes in force on a Grass model 7 oscillographic recorder. The baths were filled with $20 \mathrm{ml}$ of K-H buffer and aerated at $37^{\circ} \mathrm{C}$ with a gas mixture of $95 \% \mathrm{O}_{2}$ and $5 \%$ $\mathrm{CO}_{2}$. Coronary rings were initially stretched to give a preload of $0.5 \mathrm{~g}$ of force and equilibrated for $60-90 \mathrm{~min}$. During this period, the K-H buffer in the tissue baths was replaced every $20 \mathrm{~min}$. After equilibration, the rings were then exposed to $10 \mathrm{ng} / \mathrm{ml} \mathrm{U}-46619$ (Upjohn Co., Kalamazoo, MI), a thromboxane $A_{2}$ mimetic, to generate $\sim 0.5 \mathrm{~g}$ of developed force. Once a stable contraction was obtained, $0.1,1,10$, and $100 \mathrm{nM}$ acetylcholine ( $\mathrm{ACh}$ ) was added to the bath. After the response stabilized, the rings were washed and allowed to equilibrate to baseline once again. The procedure was repeated with A-23187 $(1,10,100$, and $1000 \mathrm{nM})$ and then to $\mathrm{NaNO}_{2}(0.1,1,10$, and $100 \mu \mathrm{M}) . \mathrm{NaNO}_{2}$ was prepared by dissolving the compound in $0.1 \mathrm{~N} \mathrm{HCl}$ and titrating it to $\mathrm{pH}$ 2.0. Titrating distilled water to $\mathrm{pH} 2.0$ and adding aliquots to buffer in the bath did not produce any vasorelaxation.

In neutrophil adherence studies, opened cat coronary rings were placed in $5 \mathrm{ml}$ of $\mathrm{K}-\mathrm{H}$ buffer, and $100 \mathrm{nM}$-methionyl-leucyl-phenylalanine and 400,000 labeled neutrophils/ml were added. Coronary rings were removed $20 \mathrm{~min}$ later for fluorescence microscopy, and the numbers of neutrophils adhering to the endothelial surface was counted and averaged per $100 \times$ magnification field.

Determination of tissue myeloperoxidase. The myocardial activity of myeloperoxidase (MPO), an enzyme occurring virtually exclusively in neutrophils, was determined using the method of Bradley et al. (14) as modified by Mullane et al. (15). The myocardium was homogenized in $0.5 \%$ hexadecyltrimethyl ammonium bromide (HTAB) (Sigma Chemical Co., St. Louis, MO) and dissolved in $50 \mathrm{mM}$ potassium phosphate buffer (pH 6) using a Polytron (PCU-2) homogenizer (Kinemutica GmbH, Luzern, Switzerland). Homogenates were centrifuged at $12,500 \mathrm{~g}, 2^{\circ} \mathrm{C}$ for $30 \mathrm{~min}$. The supernatants were then collected and reacted with $0.167 \mathrm{mg} / \mathrm{ml}$ of $o$-dianisidine dihydrochloride (Sigma Chemical Co.) and $0.0005 \% \mathrm{H}_{2} \mathrm{O}_{2}$ in $50 \mathrm{mM}$ phosphate buffer at $\mathrm{pH}$ 6.0. The change in absorbance was measured spectrophotometrically at $460 \mathrm{~nm} .1 \mathrm{U}$ of MPO is defined as that quantity of enzyme hydrolyzing $1 \mu \mathrm{mol}$ of peroxide $/ \mathrm{min}$ at $25^{\circ} \mathrm{C}$.

Labeling of neutrophils. Autologous cat neutrophils were labeled using the Zynaxis PKH2 dye (Zynaxis Cell Science, Inc., Malvern, PA) based on the procedure of Yuan and Fleming (16). $1 \mathrm{ml}$ of diluent was added to a loose cell pellet containing $<10,000,000$ cells. $1 \mathrm{ml}$ of PKH2-GL dye $(4 \mu \mathrm{M})$ was then added to the cell suspension and then mixed for $5 \mathrm{~min}$ by inversion. $2 \mathrm{ml}$ of PBS (containing 10\% plateletpoor plasma in PBS) was added to stop the reaction and another $5 \mathrm{ml}$ of PBS was underlayered in the suspension. Cells were then centrifuged at $400 \mathrm{~g}$ for $10 \mathrm{~min}$ at room temperature. Supernatant was removed and the cells were resuspended in PBS and then recounted. Labeling procedure yields cells possessing normal morphology and function (17).

Statistical analysis. All values in the text, table, and figures are presented as means \pm standard error of the means of $n$ independent experiments. All data were subjected to ANOVA followed by the Bonferroni correction for post-hoc $t$ test. Probabilities of 0.05 or less were considered to be statistically significant.

\section{Results}

In preliminary studies, we observed that administration of MAbR 15.7 intravenously at a dose of $1 \mathrm{mg} / \mathrm{kg}$ had no effect on any of the hemodynamic or electrocardiographic variables observed in nonischemic control cats. There were no significant differences in any of the variables observed initially between 
the two MI groups of cats. Table I summarizes the ST-segment elevation and the PRI in the two MI groups. Within a few minutes of LAD occlusion, the ST-segment became elevated and peaked at 20-40 min after coronary occlusion. At reperfusion, the ST-segment decreased to close to control values. All cats subjected to MI exhibited a comparable increase in ST-segment elevation, indicating that the ischemic insult was similar between the two MI groups. Immediately after coronary occlusion, PRI decreased, resulting in a significant decrease in myocardial oxygen demand. Thereafter, the PRI increased gradually and returned to the preocclusion level at the end of the experiment. There were no significant differences between groups at any of the hourly readings. This lack of a significant difference in PRI between groups suggests that administration of MAbR15.7 has no significant effect on myocardial oxygen demand during myocardial ischemia and reperfusion. At reperfusion, there was a noticeable increase in the incidence of premature ventricular contractions (PVCs). One cat in each group developed ventricular fibrillation which was resistant to cardioversion, and were thus excluded from further study. There was no overall difference between MI groups in the number of PVCs occurring postreperfusion, indicating that MAbR15.7 does not appear to exert any major anti-arrhythmic effect.

Plasma CK activity was measured hourly during the course of the 6-h experimental period. A significant washout of CK into circulating blood occurred $30 \mathrm{~min}$ after reperfusion in MI cats receiving only the control antibody. These elevated plasma $\mathrm{CK}$ activities remained higher for the remaining $4 \mathrm{~h}$. In contrast, MI cats treated with MAbR15.7 developed significantly lower plasma CK activities compared with MI cats treated with the control antibody at every time point after reperfusion (see Fig. 1). This was not due to a direct effect of MAbR15.7 on the CK assay, as addition of MAbR 15.7 directly to cat plasma did not affect the $\mathrm{CK}$ assay results (i.e., duplicate values with and without exogenously added MAbR 15.7 were within $5 \%$ of each other). Thus, four plasma samples drawn from untreated MI cats at $6 \mathrm{~h}$ were $47 \pm 5 \mathrm{IU} / \mathrm{mg}$ protein $\times 10^{-3}$ vs. $45 \pm 4 \mathrm{IU} / \mathrm{mg}$ protein $\times 10^{-3}$ in these same samples reassayed in the presence of $20 \mu \mathrm{g} / \mathrm{ml}$ of MAbR15.7.

To verify plasma CK activity as an index of preservation of ischemic tissue, and to ascertain the effects of MAbR15.7 on the degree of myocardial salvage of ischemic or necrotic tissue after reperfusion, we also measured the area-at-risk of the ischemic heart and the amount of necrotic cardiac tissue expressed as a percentage of either the area-at-risk or of the total left ventricular mass (Fig. 2). There is no significant difference in area-at-risk expressed as percentage of total left ventricle between groups, indicating a comparable initial ischemic insult existed. However, the necrotic area either expressed as percentage of area-at-risk or of total left ventricular mass was signifcantly lower in cats treated with MAbR15.7 than that observed in cats receiving the control antibody. Thus, administration of MAbR15.7 significantly prevented myocardial damage induced by ischemia and reperfusion.

Infiltration of the ischemic region by neutrophils during reperfusion has been thought to be one of the major mechanisms responsible for reperfusion injury. We measured MPO activity of the three different portions of the myocardium as a marker for neutrophil adherence. These results are summarized in Fig. 3. It is evident that in the nonischemic myocardium (i.e., area-not-at-risk), MPO activity was very low in both MI groups and there was no significant difference between them, indicating that there was no significant infiltration of neutrophils in the nonischemic myocardium. However, MI cats receiving the control antibody exhibited a marked increase in MPO activity in the ischemic region, with a 10- to 12 -fold increase in MPO activity in the necrotic myocardium. In contrast, MAbR15.7-treated ischemic cats showed a significant decrease in MPO activity, both in ischemic-nonnecrotic and in necrotic myocardial tissue. This result indicates that adherence and infiltration of neutrophils to ischemic myocardium was significantly inhibited by MAbR15.7.

Because endothelial cells exert a very important role in ischemia and reperfusion injury, we also tested endothelial integrity as measured by vasoactivity of coronary artery rings to the endothelium-dependent vasodilators, $\mathrm{ACh}$, and $\mathrm{A}-23187$, and to the endothelium-independent vasodilator, $\mathrm{NaNO}_{2}$. Fig. 4 illustrates a typical recording of ischemic LAD coronary rings obtained from cats either receiving MAbR3.1 (top) or MAbR15.7 (bottom). The response of coronary rings obtained from MI group receiving the control antibody to the endothelium-dependent vasodilator, $\mathrm{ACh}$, was totally abolished at $\mathbf{4 . 5}$ $h$ postreperfusion. However, coronary rings relaxed fully when the endothelium-independent vasodilator, $\mathrm{NaNO}_{2}$, was added, indicating that the responsiveness of the vascular smooth muscle to vasodilators are still normal. On the other hand, rings obtained from cats treated with MAbR15.7 significantly relaxed to both endothelium-dependent vasodilators (i.e., ACh and A-23187), as well as the endothelium-independent vasodi-

Table I. ST-Segment Elevations and PRI in Cats Subjected to Myocardial Ischemia and Reperfusion

\begin{tabular}{|c|c|c|c|c|c|c|c|c|}
\hline \multirow[b]{2}{*}{ Variable } & \multirow[b]{2}{*}{ Group } & \multicolumn{7}{|c|}{ Time } \\
\hline & & 0 & 1 & 2 & 3 & 4 & 5 & 6 \\
\hline & & & & & $h$ & & & \\
\hline \multirow{3}{*}{$\begin{array}{l}\text { ST-segment elevation } \\
\quad(m V)\end{array}$} & MI + MAbR3.1 & $0 \pm 0$ & $0.16 \pm 0.04^{*}$ & $0.11 \pm 0.05$ & $0.08 \pm 0.03$ & $0.03 \pm 0.02$ & $0.01 \pm 0.01$ & $0 \pm 0$ \\
\hline & MI + MAbR 15.7 & $0 \pm 0$ & $0.17 \pm 0.05^{*}$ & $0.11 \pm 0.03$ & $0.07 \pm 0.03$ & $0.04 \pm 0.02$ & $0.01 \pm 0.01$ & $0 \pm 0$ \\
\hline & & NS & NS & NS & NS & NS & NS & NS \\
\hline \multirow[t]{3}{*}{ PRI (HR • MABP/1000) } & MI + MAbR3.1 & $22 \pm 3$ & $18 \pm 2$ & $17 \pm 3$ & $17 \pm 2$ & $18 \pm 3$ & $18 \pm 2$ & $19 \pm 2$ \\
\hline & MI + MAbR15.7 & $23 \pm 3$ & $17 \pm 3$ & $18 \pm 3$ & $16 \pm 2$ & $19 \pm 2$ & $20 \pm 3$ & $21 \pm 3$ \\
\hline & & NS & NS & NS & NS & NS & NS & NS \\
\hline
\end{tabular}

All values are means \pm SEM for $6 \mathrm{MI}+$ MAbR3.1 cats or $7 \mathrm{MI}+$ MAbR15.7 cats. ${ }^{*} P<0.02$ from 0 time. NS, Not significant between groups. 


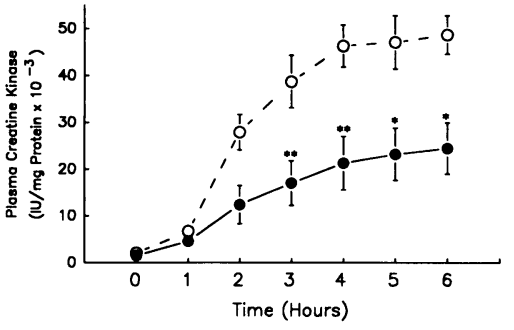
and increases significantly after reperfusion in cats given MAbR3.1, clonal antibody directed against CD-18. MI + MAbR 3.1 (- - -) MI + MAb R15.7 (一•-)

lator, $\mathrm{NaNO}_{2}$. Fig. 5 summarizes the statistical evaluation of the vasorelaxant response to $\mathrm{ACh}, \mathrm{A}-23187$, and $\mathrm{NaNO}_{2}$ in isolated cat LAD coronary artery rings. Clearly, the response of ischemic LAD coronary rings to the endothelium-dependent vasodilators was significantly preserved in the MAbR15.7treated cats. Fig. 6 illustrates the vasorelaxant response of paired LCX coronary rings studied as a control. The nonischemic LCX rings, whether obtained from untreated group or antibody-treated ischemic cats showed equally well and complete relaxant response to $\mathrm{ACh}, \mathrm{A}-23187$, and $\mathrm{NaNO}_{2}$. There were no significant differences in response to any of the vasodilators studied between the two groups of LCX coronary artery rings.

To test whether MAbR15.7 has any direct effect on coronary artery tone, additional experiments were done using the LAD coronary artery rings from control nonischemic cats. After precontraction of these LAD rings with U-46619, MAbR 15.7 was added to the bath. Neither vasoconstrictor nor vasodilator effects were observed at antibody concentrations of 2 and $20 \mu \mathrm{g} / \mathrm{ml}$. At $2 \mu \mathrm{g} / \mathrm{ml}$, MAbR 15.7 increased developed force by $27 \pm 19 \mathrm{mg}$ in seven coronary artery rings, and at 20 $\mu \mathrm{g} / \mathrm{ml}$ the antibody decreased developed force by $34 \pm 23 \mathrm{mg}$. Neither value is significantly different from 0 . Therefore, the observed cardioprotective effects of MAbR 15.7 on reperfusion injury cannot be explained by any direct coronary vasodilator effect of the antibody.

In addition, MAbR15.7, at a concentration of $20 \mu \mathrm{g} / \mathrm{ml}$, virtually totally inhibited the adherence of autologous cat neutrophils onto isolated cat coronary artery rings. By use of a fluorescent cell membrane dye (PKH2) added to isolated cat neutrophils activated with f-methionyl-leucyl-phenylalanine, we obtained results employing seven to ten rings in each group. Fig. 7 shows that very few nonactivated neutrophils adhered to

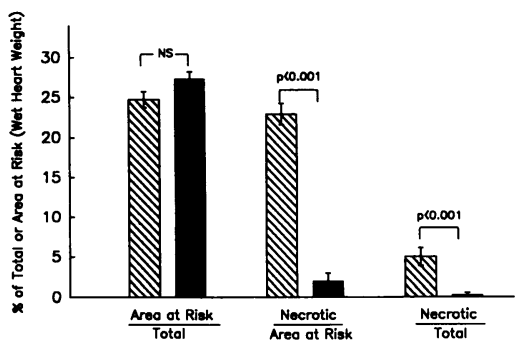

Figure 2. Tissue wet weight of area-at-risk as a percentage of the total left ventricular wet weight, and of necrotic tissue as a percentage of area-at-risk and of the total left ventricle for the two MI groups. Height of bars are means, brackets represent \pm SEM for six to seven samples MI + MAbR 3.1 (ه). MI + MAbR 15.7 (ם).

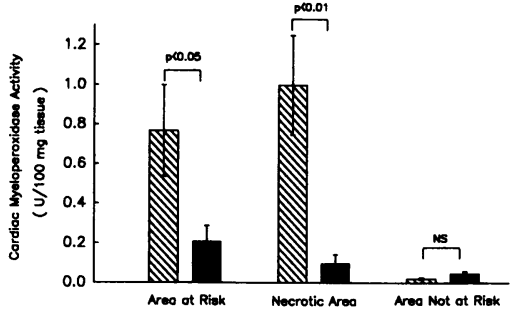

Figure 3. MPO activity in area-at-risk, necrotic area, and area-not-atrisk in $\mathrm{U} / 100 \mathrm{mg}$ tissue wet weight for the two MI groups. Height of bars are means, brackets represent SEM for six to seven samples. MI + MAbR 3.1 (घ). MI + MAbR 15.7 (घ).

coronary endothelium, whereas large numbers of fMLP (100 nM)-activated neutrophils adhered (i.e., 12 times the number of unstimulated neutrophils) $(P<0.01)$. In contrast, MAbR15.7 added to the Krebs-Henseleit solution bathing the coronary artery rings almost totally inhibited all neutrophils (i.e., 97\% inhibition) from adhering to the coronary endothelium, whereas the control antibody (MAbR3.1) was without any significant effect on inhibiting adherence of PMNs to cat coronary endothelium. These results clearly show that the antiCD18 antibody is effective in preventing cat neutrophils from adhering to cat coronary endothelium.

\section{Discussion}

It is now well recognized that the introduction of oxygen, calcium, and neutrophils, into a previously ischemic myocardium can initiate a deleterious cascade of events during reperfusion, including injury to myocytes and endothelial cells (2). There is growing evidence to suggest that neutrophils play a central, deleterious role in reperfusion injury after ischemia. Histologic studies by Sommers and Jennings (18) demonstrated that neutrophils are visible in ischemic myocardial tissue within $50 \mathrm{~min}$ of reperfusion after coronary occlusion for $\mathbf{4 0} \mathrm{min}$. Biochemical studies indicate that myocardial myeloperoxidase activity, which correlates with the histologic extent of neutrophil infiltration, exhibited a 23 -fold increase after 90 min of ischemia
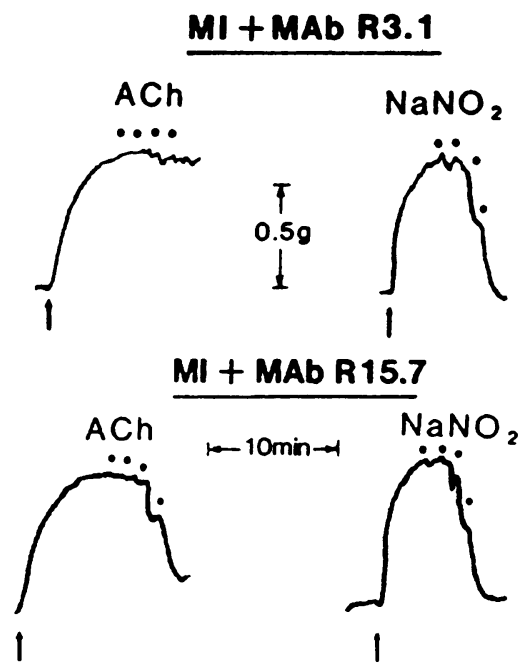
cat, whereas ACh response of rings isolated from a MAbR 15.7-treated MI cat was significantly preserved. 


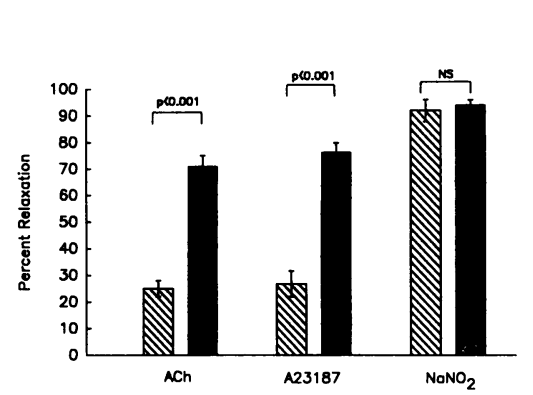

Figure 5. Summary of responses of ischemiareperfused $L A D$ rings to $100 \mathrm{nM}$ ACh, $1 \mu \mathrm{M}$ A23187, and $100 \mu \mathrm{M}$ $\mathrm{NaNO}_{2}$. Bar heights are means, brackets indicate \pm SEM for 8-10 rings. MI + MAbR 3.1 (ه). MI + MAbR 15.7 (a).

followed by $5 \mathrm{~h}$ of reperfusion in dogs (15). Additional support for the concept of neutrophil-mediated myocardial injury has been obtained in neutropenic or neutrophil blocked animals during myocardial ischemia and reperfusion (6). Other experiments show that inhibitors of 5-lipoxygenase metabolism (19), prostacyclin, or its analogues $(20,21)$, or agents that inhibit the activation of neutrophils (21) are also effective in reducing experimental myocardial injury during reperfusion by reducing the extent of neutrophil accumulation within the previously ischemic myocardium.

It is proposed that neutrophil adherence to endothelial cells is a prerequisite for deleterious effects of these leukocytes on endothelium and myocardium $(22,23)$. Immunological studies have demonstrated that a family of heterodimeric glycoproteins possessing a common $\beta$-chain (CD-18) and one of three separate $\alpha$-chains (i.e., CD11a, CD11b, or CD11c) are expressed on the surface of the neutrophils (24). It has been well recognized that the CD11/CD-18 glycoprotein family plays a critical role in neutrophil adherence (25). Antibodies either directed against the common $\beta$-chain, CD-18 (MAb 60.3) (26, 27), $\mathrm{MAb} \mathrm{IB}_{4}(28)$, or against separate $\alpha$-chains, CD11a (TS1/ 22) (29) and CD1 lb (MAb 60.1) (30) significantly inhibit the adherence of neutrophils to the endothelium by an effect on neutrophils rather than direct effects on their endothelial ligands. However, it has recently been proposed that the relative importance of the three separate $\alpha$-chains in the adherence of neutrophils to endothelium varies and is dependent on "activation states" of both the neutrophils and the endothelial cells. Arnaout et al. (31) have demonstrated that PMA-induced adhesion of granulocytes to endothelial cells was mediated primarily by CD-1 1b/CD-18. Moreover, this process was not inhibited by monoclonal antibodies against CD-11a/CD-18 or CD-11c/CD-18. On the other hand, Smith et al. (32) have shown that unstimulated neutrophils adhere to human umbilical vein endothelium in vitro via $C D-11 \mathrm{a} / \mathrm{CD}$-18-dependent attachment to intercellular adhesion molecule-1 (ICAM-1), whereas neutrophils stimulated with chemoattractant adhere to these endothelial cells via a CD-11b/CD-18-dependent at-

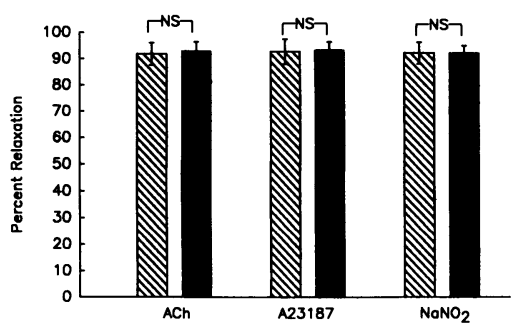

Figure 6. Summary of responses of nonischemic LCX coronary rings to $100 \mathrm{nM}$ ACh, $1 \mu \mathrm{M}$ A-23187, and $100 \mu \mathrm{M}$ $\mathrm{NaNO}_{2}$. Bar heights are means, brackets indicate \pm SEM for 8-10 rings. MI + MAbR 3.1 (ब). MI + MAbR 15.7 (a).
Figure 7. Effects of MAbR15.7 and MAbR3.1 on neutrophil adherence to cat coronary endothelium. Data are expressed as numbers of PMNs per field of magnification. Bar heights are means, brackets indicate \pm SEM, and numbers at the bottom of the bars are numbers of coronary rings studied. fMLP concentration = $100 \mathrm{nM}$.

tachment mechanism via ICAM-1 receptors. Because a variety of "activation states" of the neutrophils and endothelium may occur at different times during myocardial ischemia and reperfusion, the antibody that is specifically directed to one of the $\alpha$-chains of the CD-11 family of glycoproteins may not fully inhibit neutrophil adherence. Additional studies on endothelial function in coronary veins would also be a fruitful area of investigation because venous endothelium is thought to be a more critical site of neutrophil adherence than the arterial endothelium.

Our results clearly show that administration of an antibody to the common $\beta$-chain of the adhesive glycoprotein family (i.e., CD-18) before reperfusion has significant protective effects on endothelial dysfunction and myocardial injury induced by myocardial ischemia and reperfusion. Interestingly, compared with other results obtained from employing an antibody directed against one of the $\alpha$-chains, Anti-Mol $904^{10}$ or its $\mathrm{F}\left(\mathrm{ab}^{\prime}\right)_{2}$ fragments (33) on myocardial reperfusion injury in a dog model, we have observed a greater suppression of neutrophil accumulation in ischemic myocardium and a greater cardioprotective effect with an antibody directed against common $\beta$-chain in a cat ischemia/reperfusion model. Whether this reflects a difference in the efficacies of the antibodies or whether it represents differences between cat or dog ischemia models remains to be tested. In this regard, MAbR15.7 exerted the most striking anti-ischemic event of any agent we have ever studied in our model of reperfusion injury. Although it appears that MAbR 15.7 protects against the cardiac injury due to both the direct ischemic as well as the reperfusion phases of the myocardial ischemia-reperfusion protocol, this is not entirely the case. In this cat model of ischemia-reperfusion, Tsao et al. (34) have shown that 90 min of permanent occlusion results in a percentage of necrosis/AAR of only $1.2 \pm 0.9 \%$. This only increases to $6.9 \pm 2.2 \%$ at $4.5 \mathrm{~h} \mathrm{(35)}$. Thus, in the cat model of LAD occlusion, the early injury due to direct ischemia is not great. It requires longer times to develop significant injury. At $24 \mathrm{~h}$, significant injury to the left ventricle occurs (i.e., $20 \%$ of the left ventricle or $75 \%$ of the area-at-risk) (36). Recently, Welbourn et al. (37) using MAbR15.7 in hindlimb ischemia and reperfusion in rabbits, found that this antibody reduced neutrophil diapedesis into dermabrasion chambers by over $99 \%$, and was much more effective than a leukotriene $B_{4}$ receptor antagonist in this regard. These findings help explain the remarkably effective results in curtailing myocardial injury in our experiments. Of course, we cannot exclude other more subtle effects 
of the antibody on preserving endothelial function in vivo which could, if they occur, contribute to the anti-ischemic effect.

The endothelial-preserving effect of MAbR15.7 in our experiments presumably occurs within the first $20 \mathrm{~min}$ after reperfusion when 65 to $75 \%$ of the endothelial dysfunction occurs (34). This is before significant infiltration of neutrophils into the ischemic area (34). Our findings can be explained by either $(a)$ a direct endothelial protective effect of MAbR 15.7, or (b) a protective effect of this antibody on neutrophils preventing their activation and release of cytotoxic mediators after reperfusion. Among these mediators, free radicals are generally considered to be the most significant cytotoxic products derived from activation of neutrophils (38). In this connection, superoxide ions have been shown to inactivate EDRF (39), initiate lipid peroxidation, and alter membrane permeability to ions, all of which can lead to significant endothelial dysfunction. In addition, TNF significantly inhibits EDRF release from cat carotid and coronary arteries stimulated by ACh (40). Although we cannot explicitly differentiate between these two possibilities, inhibition of the release of mediators from the activated neutrophil is probably the more likely mechanism of endothelial protection by MAbR15.7.

Several possibilities may explain the protective mechanism of antibody MAbR 15.7 on myocardial cell injury which occurs along with neutrophil accumulation at $3 \mathrm{~h}$ after reperfusion in this model of ischemia and reperfusion (34). First, it is well recognized that neutrophils release a variety of mediators that directly promote myocardial tissue injury, including proteolytic enzymes, platelet activating factor, arachidonic acid metabolites, and oxygen-derived free radicals (4). Because neutrophil activation is a prerequisite for the release of these cytotoxic products, MAbR15.7 may exert its cardioprotective effect by inhibiting the neutrophil adherence to endothelium and subsequent diapedesis into the myocardium, thereby reducing the release of deleterious mediators of neutrophil origin into the environment of ischemic myocardial cells. In this connection, we have previously shown that cat neutrophils in the presence of f-MLP induce coronary vasoconstriction and retard endothelium-dependent vasorelaxation in coronary artery rings isolated from cats subjected to myocardial ischemia and reperfusion (41). Moreover, addition of MAbR15.7 markedly inhibit the neutrophil-mediated inhibitory process of endothelial function. We now have provided evidence that the antibody (i.e., MAbR 15.7) inhibits adherence of neutrophils to the coronary vascular endothelium.

Second, activated neutrophils can release a variety of cytokines, including IL-1 and TNF, which may facilitate myocardial injury induced by neutrophils coming in contact with myocytes. MAbR 15.7, by inhibiting neutrophil adherence and activation, should eliminate many of the deleterious effects of neutrophils on myocardial cells. Moreover, MAbR15.7 has recently been shown to inhibit neutrophil adherence to isolated canine cardiac myocytes by more than $95 \%$ and to reduce neutrophil release of $\mathrm{H}_{2} \mathrm{O}_{2}$ by at least $90 \%$ (42). Our findings of a decreased adherence of cat neutrophils to cat coronary endothelium would also support a marked protective effect of MAbR15.7 on the ischemic myocardium.

Third, aggregated neutrophils can mechanically obstruct capillaries and thereby inhibit reperfusion of ischemic tissue, thus contributing to exacerbation of the infarction process (43). It is also possible that MAbR15.7 can exert its protective effects by inhibiting neutrophil aggregation, and thus preventing microvascular obstruction and subsequent myocardial injury.

Although MAbR15.7 effectively reduced ischemic damage in our experiments and those of Winquist (10), it should be mentioned that other monoclonal antibodies against CD-18 have not been very effective in retarding postreperfusion ischemic injury. Thus, MAb MHM23 (44) and $\mathrm{IB}_{4}$ (45) failed to reduce ischemic injury in dogs after circumflex occlusion and reperfusion. Whether this is due to differences in experimental methods or to properties of these antibodies in recognizing different epitopes cannot be determined at present.

In conclusion, we have observed that occlusion of the LAD coronary artery for $90 \mathrm{~min}$ followed by $4.5 \mathrm{~h}$ reperfusion resulted in a significant neutrophil accumulation in the ischemic myocardium, endothelial dysfunction, and myocardial injury. Administration of a monoclonal antibody directed against the common $\beta$-chain of neutrophil adherence glycoproteins (i.e., CD-18, MAbR15.7) significantly inhibited neutrophil adherence to isolated cat coronary endothelium and retarded accumulation in ischemic myocardial tissue in vivo, and thereby exerted a significant endothelial and cardioprotective effect in myocardial ischemia and reperfusion.

\section{Acknowledgments}

We gratefully acknowledge the assistance of Gerald Johnson III and Phillip A. Taylor III during the course of this investigation. We also thank Dr. Raymond J. Winquist and Dr. Robert Rothlein of Boehringer-Ingelheim Pharmaceuticals, Inc., Ridgefield, CT, for the generous supply of the antibodies used in this study and for characterizing their properties in cat leukocytes.

Supported in part by research grant HL-25575 from the National Heart, Lung, and Blood Institute of the National Institutes of Health. P. S. Tsao is a Predoctoral Trainee (NIH, HL-07599).

\section{References}

1. Braunwald, E., and R. A. Kloner. 1985. Myocardial reperfusion: a doubleedged sword? J. Clin. Invest. 76:1713-1719.

2. Forman, M. B., R. Virmani, and D. W. Puett. 1990. Mechanisms and therapy of myocardial reperfusion injury. Circulation. 81(Suppl):IV69-IV78.

3. Kloner, R. A., S. G. Ellis, E. Lange, and E. Braunwald. 1985. Studies of experimental coronary artery reperfusion: Effects on infarct size, myocardial function, biochemistry, ultrastructure, and microcirculation damage. Circulation. 58(Suppl):I1-18.

4. Lucchesi, B. R., S. W. Werns, and J. C. Fantone. 1989. The role of the neutrophil and free radicals in ischemic myocardial injury. J. Mol. Cell. Cardiol. 21:1241-1251.

5. Engler, F. L., M. D. Dahlgren, D. Morris, M. A. Peterson, and G. SchmidSchoenbein. 1986. Role of leukocytes in the response to acute myocardial ischemia and reflow in dogs. Am. J. Physiol. 251:H314-H323.

6. Romson, J. L., B. G. Hook, S. L. Kunkel, G. D. Abrams, M. A. Schork, and B. R. Lucchesi. 1983. Reduction of the extent of ischemic myocardial injury by neutrophil depletion in the dog. Circulation. 67:1016-1023.

7. Bednar, M., B. Smith, A. Pinto, and K. M. Mullane. 1985. Nafazatrom-induced salvage of ischemic myocardium in anesthetized dogs is mediated through inhibition of neutrophil function. Circ. Res. 57:131-141.

8. Wallis, W. J., P. G. Beatty, H. D. Ochs, and J. M. Harlan. 1985. Human monocyte adherence to cultured vascular endothelium: monoclonal antibodydefined mechanisms. J. Immunol. 135:2323-2334.

9. Simpson, P. J., R. F. Todd, J. C. Fantone, J. K. Michelson, J. D. Griffin, and B. R. Lucchesi. 1988. Reduction of experimental canine myocardial reperfusion injury by a monoclonal antibody (anti-Mol, anti-CD1 1b) that inhibits leukocyte adhesion. J. Clin. Invest. 81:624-629.

10. Winquist, R. P. Frei, P. Harrison, M. McFarland, G. Letts, G. Van, L. Andrews, R. Rothlein, and T. Hintze. 1990. An anti-CD-18 Mab limits infarct size in primates following ischemia and reperfusion. Circulation. 82:III-701a. (Abstr.)

11. Dreyer, W. J., L. H. Michael, M. S. West, C. W. Smith, R. Rothlein, R. D. Rossen, D. C. Anderson, and M. L. Entman. 1991. Neutrophil accumulation in ischemic canine myocardium. Circulation. 84:400-411. 
12. Gornall, A. G., C. T. Bardowill, and M. M. David. 1949. Determination of serum protein by means of the biuret method. J. Biol. Chem. 177:751-766.

13. Rosalki, S. B. 1967. An improved procedure for serum creatine phosphokinase determination. J. Lab. Clin. Med. 69:696-705.

14. Bradley, P. P., D. A. Priebat, R. D. Christensen, and G. R. Rothstein. 1982. Measurement of cutaneous inflammation: Estimation of neutrophil content with an enzyme marker. J. Invest. Dermatol. 78:206-209.

15. Mullane, K. M., R. Kraemer, and B. Smith. 1985. Myeloperoxidase activity as an assessment of neutrophil infiltration into ischemic myocardium. J. Pharmacol. Methods. 14:157-167.

16. Yuan, Y., and B. P. Fleming. 1990. A method for isolation and fluorescent labeling of rat neutrophils for intravital microvascular studies. Microvasc. Res. 40:218-229.

17. Horan, P. K., and S. E. Slezak. 1989. Stable cell membrane labelling. Nature (Lond.). 340:167-168.

18. Sommers, H. M., and R. B. Jennings. 1964. Experimental acute myocardial infarction: histologic and histochemical studies of early myocardial infarcts induced by temporary and permanent occlusion of a coronary artery. Lab. Invest. 13:1391-1503.

19. Romson, J. L., B. G. Hook, V. H. Rigot, M. A. Schork, D. P. Swanson, and B. R. Lucchesi. 1982. The effect of ibuprofen on accumulation of III-indium labeled platelets and leukocytes in experimental myocardial infarction. Circulation. 66:1002-1011.

20. Simpson, P. J., S. E. Mitsos, A. Ventura, K. P. Gallagher, J. C. Fantone G. D. Abrams, M. A. Schork, and B. R. Lucchesi. 1987. Prostacyclin protects ischemic reperfused myocardium in the dog by inhibition of neutrophil activation. Am. Heart J. 113:129-137.

21. Johnson III, G., L. E. Furlan, N. Aoki, and A. M. Lefer. 1990. Endothelium and myocardial protecting actions of taprostene, a stable prostacyclin ana$\log$, after acute myocardial ischemia and reperfusion in cats. Circ. Res. 66:1362 1370.

22. Nathan, C. F. 1987. Neutrophil activation on biological surfaces. Massive secretion of hydrogen peroxide in response to products of macrophages and lymphocytes. J. Clin. Invest. 80:1550-1560.

23. Nathan, C. F. 1989. Respiration burst in adherent human neutrophils: triggering by colony-stimulating factors CSF-GM and CSF-G. Blood. 73:301306.

24. Todd, R. F., III, and D. R. Freyer. 1988. The CD11/CD18 leukocyte glycoprotein deficiency. Hem./Oncol. Clin. N. Am. 2:13-31.

25. Tonnesen, M. G. 1989. Neutrophil-endothelial cell interactions: mechanisms of neutrophil adherence to vascular endothelium. J. Invest. Dermatol. 93:53S-58S.

26. Price, T. H., P. G. Beatty, and S. R. Gorpuy. 1987. In vivo inhibition of neutrophil function in the rabbit using monoclonal antibody to CD18. J. Im munol. 139:4174-4177.

27. Hernandez, L. A., M. B. Grisham, B. Twohig, K. E. Arfors, J. M. Harlan, and D. M. Granger. 1987. Role of neutrophils in ischemia-reperfusion-induced microvascular injury. Am. J. Physiol. 253:H699-H703.

28. Suzuki, M., W. Inauen, P. R. Kvietys, M. B. Grisham, C. Meininger, M. E Schelling, H. J. Granger and D. N. Granger. 1989. Superoxide mediates reperfusion-induced leukocyte-endothelial cell interactions. Am. J. Physiol. 257:H1740 H1745.

29. Smith, C. W., S. D. Marlin, R. Rothlein, C. J. Tomman, H. K. Hawkins, and D. C. Anderson. 1988. LFA-1 and ICAM-1 in neutrophil adherence and transendothelial migration. J. Leukocyte Biol. 44:293a. (Abstr.)
30. Zimmerman, G. A., and T. M. McIntyre. 1988. Neutrophil adherence to human endothelium in vitro occurs by CDW18 (Mol, Mac-1/LFA-1/GP 150,95) glycoprotein-dependent and -independent mechanisms. J. Clin. Invest. 81:531537.

31. Arnaout, M. A., L. L. Lanfer, and D. V. Faller. 1988. Relative contribution of the leukocyte molecules Mol, LFA-1 and p150,95 (Leum5) in adhesion of granulocytes and monocytes to vascular endothelium is tissue- and stimulus specific. J. Cell. Physiol. 137:305-309.

32. Smith, C. W., S. D. Marlin, R. Rothlein, C. Toman, and D. Anderson. 1989. Cooperative interactions of LFA-1 and Mac-1 with intercellular adhesion molecule- 1 in facilitating adherence and transendothelial migration. J. Clin. Invest. 83:2008-2017.

33. Simpson, P. J., R. F. Todd III, J. K. Mickelson, J. C. Fantone, K. P. Gallagher, K. A. Lee, Y. Tamura, M. Cronin, and B. R. Lucchesi. 1990. Sustained limitation of myocardial reperfusion injury by a monoclonal antibody that alters leukocyte function. Circulation. 81:226-237.

34. Tsao, P. S., N. Aoki, D. J. Lefer, G. Johnson III, and A. M. Lefer. 1990. Time course of endothelial dysfunction and myocardial injury during myocardial ischemia and reperfusion in the cat. Circulation. 82:1402-1412.

35. Viehman, G., X.-I. Ma, D. J. Lefer, and A. M. Lefer. 1991. Time course of endothelial dysfunction and myocardial injury during coronary arterial occlusion. Am. J. Physiol. 261:H874-H881.

36. Smith III E. F., G. A. Schmunk, B. A. Carrow, and A. M. Lefer. 1982. Infarct size restriction in cats by the $\beta$-adrenergic blocker timolol. Eur. J. Pharmacol. 77:153-158.

37. Welbourn, R., G. Goldman, L. Kobzik, I. Paterson, C. R. Valeri, D. Shepro, and H. B. Hechtman. 1990. Neutrophil adherence receptors (CD 18) in ischemia. Dissociation between quantitative cell surface expression and diapedesis mediated by leukotriene $B_{4}$. J. Immunol. 145:1906-1911.

38. Werns, S. W., and B. R. Lucchesi. 1990. Free radicals and ischemic tissue injury. Trends Pharmacol. Sci. 11:161-166.

39. Rubanyi, G. M., and P. M. Vanhoutte. 1987. Oxygen-derived free radicals, endothelial and responsiveness of vascular smooth muscle. Am. J. Physiol. 250:H815-H821.

40. Aoki, N., M. Siegfried, and A. M. Lefer. 1989. Anti-EDRF effect of tumor necrosis factor in isolated perfused cat carotid arteries. Am. J. Physiol. 256:H1509-H1512.

41. Ma, X.-L., P. S. Tsao, G. E. Viehman, and A. M. Lefer. 1991. Neutrophilmediated vasoconstriction and endothelial dysfunction in low-flow perfusion-reperfused cat coronary artery. Circ. Res. 69:95-106.

42. Entman, M. L., K. Youker, S. B. Shappell, C. Siegel, R. Rothlein, W. J. Dreyer, F. C. Schmalstieg and C. W. Smith. 1990. Neutrophil adherence to isolated adult canine myocytes. Evidence for a CD18-dependent mechanism. $J$. Clin. Invest. 85:1497-1506.

43. Engler, R. L., M. D. Dahlgren, M. A. Peterson, A. Dobbs, and G. SchmidSchoenbein. 1986. Accumulation of polymorphonuclear leukocytes during 3hour experimental myocardial ischemia. Am. J. Physiol. 251:H93-H100.

44. Richardson, C., A. DiPaula, J. Hildreth, and L. Becker. 1989. Failure of a monoclonal antibody directed against the neutrophil adhesion complex to reduce myocardial reperfusion injury. Circulation. 80:Il-401a. (Abstr.)

45. Tanaka, M., S. E. Brooks, G. P. FitzHarris, R. C. Stoler, R. B. Jennings, and $\mathrm{K}$. A. Reimer. 1990. Effect of the $\mathrm{IB}_{4}$ anti-CD18 antibody on myocardial PMN accumulation and infarct size in dogs. FASEB (Fed. Am. Soc. Exp. Biol.) J. 4:A1020. (Abstr.) 